\title{
Adjuvant dendritic cell vaccination in high-risk uveal melanoma patients
}

\author{
Kalijn Bol ${ }^{1 *}$, Thomas van den Bosch ${ }^{2}$, Gerty Schreibelt ${ }^{1}$, Cornelis Punt ${ }^{3}$, Carl Figdor ${ }^{1}$, Dion Paridaens ${ }^{2}$, \\ Jolanda de Vries ${ }^{1}$ \\ From 30th Annual Meeting and Associated Programs of the Society for Immunotherapy of Cancer (SITC 2015) \\ National Harbor, MD, USA. 4-8 November 2015
}

\section{Background}

The presence of monosomy 3 in the primary tumor is widely accepted as the most reliable prognostic parameter, identified in approximately $50 \%$ of patients with primary uveal melanoma [1]. Long term studies have shown a 3 -year survival rate of $40 \%$ if monosomy 3 is present, whereas tumors with normal chromosome 3 status rarely give rise to metastatic disease and have a $90 \%$ 3 -year survival rate [2]. Currently, there is no effective adjuvant treatment for the patients with early stage uveal melanoma at high risk for metastatic disease (monosomy 3). The development of uveal melanoma at an immune-privileged site, the eye, made it questionable if immunotherapy would be a suitable treatment modality. Nonetheless, in this open label Phase II study we investigated the immunological responses in high risk uveal melanoma patients, selected based on monosomy 3 , to dendritic cell vaccination.

\section{Methods}

Twenty-three patients with a primary uveal melanoma with monosomy 3 were included in this trial. HLA$A * 02: 01$ positive patients received vaccinations with autologous dendritic cells loaded with melanoma antigens gp100 and tyrosinase. The main outcome measures are safety, immunological response, progression-free and overall survival. ClinicalTrials.gov Identifier: NCT00929019.

\section{Results}

Tumor-specific immune responses were induced with dendritic cell vaccination in the majority of patients. Patients with a tumor-specific immune response showed a significant longer median progression free and overall survival compared to patients without a detectable tumor-specific immune response after dendritic cell vaccination. No severe treatment-related toxicities (common toxicity criteria grade 3 or 4 ) were observed. Updated data will be presented.

\section{Conclusions}

Dendritic cell vaccination is feasible and safe in high risk uveal melanoma patients. Despite development of uveal melanoma at an immune-privileged site, dendritic cellbased immunotherapy is potent to enhance the host's anti-tumor immunity against uveal melanoma and tumorspecific immune responses correlate with longer progression free and overall survival.

\section{Authors' details}

${ }_{1}^{1}$ RIMLS, Radboudumc, Nijmegen, Netherlands. ${ }^{2}$ Rotterdam Eye Hospital, Rotterdam, Netherlands. ${ }^{3}$ Academic Medical Center, Amsterdam, Netherlands.

Published: 4 November 2015

\section{References}

1. Prescher $\mathrm{G}$, Bornfeld N, Hirche H, Horsthemke B, Jockel KH, Becher R: Prognostic implications of monosomy 3 in uveal melanoma. Lancet 1996, 347(9010):1222-1225.

2. White VA, Chambers JD, Courtright PD, Chang WY, Horsman DE: Correlation of cytogenetic abnormalities with the outcome of patients with uveal melanoma. Cancer 1998, 83(2):354-359.

\section{doi:10.1186/2051-1426-3-S2-P127}

Cite this article as: Bol et al:: Adjuvant dendritic cell vaccination in highrisk uveal melanoma patients. Journal for ImmunoTherapy of Cancer 2015 3(Suppl 2):P127.

${ }^{1}$ RIMLS, Radboudumc, Nijmegen, Netherlands

Full list of author information is available at the end of the article 